DOI 10.37882/2223-2982.2021.03-2.33

\title{
СТРУКТУРА ЗАНЯТИЯ НА ОСНОВЕ CLIL-TEХНОЛОГИЙ В НЕЯЗЫКОВОМ ВУЗЕ
}

\section{STRUCTURE OF CLASSES BASED ON CLIL TECHNOLOGIES IN A NON-LINGUISTIC UNIVERSITY}

\section{A. Ponomareva \\ E. Yakovleva}

Summary: Globalization processes and active international cooperation in various spheres of professional activities from space exploration to tourism and trade require knowledge of foreign languages at UpperIntermediate level or higher. Content and Language Integrated Learning (CLIL) educational technologies which promote development of foreign language and linguistic-information competencies in the field of professional communication have proven to be the most effective method of improving the level of proficiency in the target language in a non-linguistic discipline.

CLIL technologies include a wide variety of methods ranging from exposure to the language environment in a foreign country with subject teachers to studying a discipline in a non-linguistic specialty in a foreign language at a local university. Both technologies involve the study of the subject through the language or discourse of the specialty, which correlates with the theory of Systemic functional linguistics and educational science. Proficient level of language competence within the framework of major subjects can be achieved in higher education institutions with a combination of language and subject knowledge often used in the course of study where the target language is a means of professional communication rather than an object of analysis.

Keywords: CLIL, Content and Language Integrated Learning, content, non-linguistic university, bilingual education, content and language learning, communication, approach, linguistic competence.
Пономарева Алиса Владиславовна

Ассистент, Финансовый Университет при Правительстве РФ avponomareva@fa.ru

Яковлева Екатерина Николаевна Ассистент, Финансовый Университет при Правительстве РФ enyakovleva@fa.ru

Аннотация: Глобализационные процессы и активное международное сотрудничество в различных сферах профессиональной деятельности человека, начиная с космонавтики, заканчивая туризмом и торговлей, обусловливают владение иностранным языком в профессиональной сфере не ниже уровня Upper-Intermediate. В качестве наиболее эффективного метода повышения уровня владения иностранным языком в неязыковых вузах зарекомендовали себя образовательные технологии Content and Language Integrated Learning

(CLIL), способствующие формированию иноязычной и лингво-информационной компетенций в сфере профессиональной коммуникации.

CLIL-технологии включают в себя различные методики, от полного погружения в языковую среду на территории иноязычного государства с преподавателями-предметниками, до изучения дисциплины по неязыковой специальности на иностранном языке в отечественном вузе. И первая, и вторая технологии включают исследование (изучение) предмета через язык или дискурс специальности, что коррелирует с теорией системно-функциональной лингвистики и педагогики. Высокий уровень языковой компетентности в рамках профессионально ориентированной подготовки может быть достигнут в высших школах при сочетании языковых и предметных знаний, регулярно используемых на практике, где целевой (иностранный) язык является средством профессиональной коммуникации, а не объектом анализа.

Ключевые слова: CLIL, Content and Language Integrated Learning, предметноязыковое интегрированное обучение, содержание, неязыковой вуз, двуязычное образование, предметно-языковое обучение, коммуникация, подход, лингвистическая компетенция.

CLIL (Content and Language Integrated Learning, B перев. с англ. - «предметноязыковое интегрированное обучение») - обобщающая дефиниция, охватывающая широкий спектр подходов к межпредметному обучению языкам, которая в настоящее время наблюдается в различных образовательных контекстах [5].

CLIL - «новая, инновационная дидактическая концепция, использование которой в системе обучения иностранным языкам предполагает интегрированное предметно-языковое обучение» [2, с. 10].

Практика сочетания языка и содержания курса по специальности как для целенаправленного лингвистического, так и для предметного обучения возникла в Ка- 
наде в середине 60-х годов XX века в рамках первых программ языкового погружения, разработанных для того, чтобы предоставить англоязычному молодому населению страны возможность изучать французский язык [9].

Термин CLIL существует с 1994 г., в научный оборот введен с 1996 г. для описания образовательных методов, в которых предметы преподаются на иностранном языке с двойной целью, а именно, для изучения дисциплины и одновременного овладения иностранным языком. CLIL - это дуальноориентированный образовательный подход, при котором дополнительный язык используется для изучения и преподавания как профессионально значимого предмета для специальности (в неязыковом вузе), так и целевого (иностранного) языка [9], достижение этой двоякой цели требует разработки особого подхода к обучению, заключающегося в том, чтобы неязыковой предмет преподавался не на иностранном языке, а с помощью иностранного языка [5; 9].

Одним из факторов успеха в применении CLILтехнологий является эгалитаризм, благодаря которому данный подход стал считаться «открывающим двери в языки для более широкого круга обучающихся» [12] и способствующим толерантному отношению к иммигрантам.

Структура обучения CLIL всегда включает тему (любая тема: от академических предметов, таких как биомеханика, летательные аппараты, юриспруденция и пр., до коммуникации в стандартных жизненных ситуациях, которой обучают в вузе) и средство обучения (иностранный язык, на котором объясняется дисциплина).

В Европе данный метод обучения (CLIL) интерпретируется как «язык через учебную программу» ('language across the curriculum') и «языковое обучение через дисциплину» ('language supported subject learning'), набирая популярность с 2000-х гг., так как объединенная Европа стала включать в себя огромное разнообразие языков, при активной и беспрерывной экспансии которых коммуникация начала играть центральную роль [7]. В России CLIL реализовывается в рамках двух подходов: «изучение содержания дисциплины в процессе овладения иностранным языком» ('content-driven education') и «изучение иностранного языка на базе предметного содержания» ('language-driven education') [3, с. 43].

Технология билингвального обучения CLIL в неязыковых вузах представляет из себя синтез «иностранного языка и предметного содержания изучаемых дисциплин в процессе профессиональной подготовки» [2, с. 43], когда изучение профессиональных дисциплин осуществляется на целевом языке, а изучение целевого (иностранного) языка реализовывается в рамках данной дисциплины (специальности). По этой причине применение
CLIL-подхода целесообразно при работе со студентами, имеющими уровень знания иностранного языка не ниже В2, так как «целевой язык, наряду с родным, выступает как средство учебно-познавательной деятельности» [2, c. 14], в противном случае знаний иностранного языка для овладения дисциплиной будет недостаточно, что снизит познавательную активность и мотивацию обучающихся. По мнению Bruton (2011) и Thi Bich Ngoc Nguyen (2019), студенты, обучающиеся по программам с применением CLIL технологий, могут начать обучение с большей мотивацией, если имеют более высокий уровень владения языком [12].

Основное отличие CLIL от других традиционных подходов, таких как CBLL (ContentBased Language Learning), заключается в «запланированной педагогической интеграции контекстуализированного контента, когнитивистики, коммуникации и культуры в практику преподавания и обучения [5; 9]. Помимо того, что это мощный инструмент, который может оказать сильное влияние на изучение языков, CLIL можно рассматривать как образовательную технологию для становления языкового разнообразия, поскольку он помогает достичь плюрилингвизма, которого придерживается Европейская комиссия с 1995 г., и междисциплинарности, поскольку он преодолевает ограничения традиционных учебных программ, представляя собой сдвиг в сторону интеграции двуязычного обучения профессиональным неязыковым дисциплинам [9].

Обучение на основе CLIL-технологий эффективизируется за счет повышения мотивации в контексте изучения профессионального языка. Многие статистические исследования подтвердили тот факт, что студенты более мотивированы и талантливы в лингвистическом и академическом отношениях, а также, что вышеупомянутые технологии привлекают более успешных студентов [10]. А именно, когда обучающиеся интересуются темой, у них появляется познавательный интерес к овладению целевым языком для профессиональной коммуникации и понимания предметного содержания предмета, лекции/семинара. При этом язык рассматривается в реальных жизненных ситуациях, в которых студент мог бы им воспользоваться на практике, что стимулирует развитие естественного языка, основанного на междисциплинарном подходе к обучению.

Согласно концепции S. Darn, CLIL предполагает долгосрочное обучение, например, студенты достигают академического уровня владения английским после 5-7 летнего обучения по двуязычной программе. При этом «свободное владение языком важнее точности, а ошибки - естественная часть обучения» [6]. Слушатели достигают свободного владения иностранным языком, используя его для различных целей: контактное и дистатное общение, онлайн и офлайн коммуникация, устная 
и письменная речь и пр., при которых важнейшим навыком является чтение аутентичных текстов, содержащих и предметную, и академическую, и разговорную лексику, словосочетания и обороты [6], что позволяет развивать интерактивные речевые способности студентов неязыковых вузов [8, р. 23; 11, р. 19].

Занятия включают аутентичный материал на изучаемом языке, в том числе, письменные тексты и видеоматериал. Это позволяет студентам слышать язык так, как на нем говорят в профессиональной среде.

Обучение с использованием CLIL-технологий является отличным инструментом для лингвистического и коммуникативного синтеза языка и профессионально направленной дисциплины при условии, что методистам учебных программ, разработчикам курсов и преподавателям удается поддерживать баланс между обучением языку и предмету, не упускать из виду содержание и цели изучения языка, не перегружать студентов чрезмерным количеством содержательной основы курса, что чревато игнорированием аспектов преподавания языка и обучения. Соответственно, CLIL-технология рассматривается как обеспечение образования, выходящего за рамки изучения языка [9].

Для преподавателей, работающих по системе CLIL в неязыковом вузе, важно не только владеть иностранным языком на высоком уровне, но и быть компетентным в профессионально-ориентированных дисциплинах, в рамках которых преподаётся язык, что предполагает постоянное взаимодействие с преподавателями-предметниками или глубокое овладение дисциплиной самостоятельно, чтобы создать для студентов актуальную языковую среду, в которой им предстоит работать по окончании вуза на практике при осуществлении международной профессиональной деятельности.

В то время как коммуникативное преподавание языка было одним из шагов к обеспечению более целостного способа преподавания и изучения языков, оно оказалось недостаточным для реализации высокого уровня аутентичности цели, которая может быть достигнута с помощью CLIL [5, p. 5]. CLIL объединяет четыре различных, но взаимокоррелирующих и контекстуализированных компонента: содержательный (предмет), коммуникативный (изучение и использование языка), когнитивный (процессы обучения и мышления) и культурный (развитие межкультурного понимания и глобальной гражданственности), призывая обучающихся быть активными участниками в развитии своего потенциала для приобретения знаний и навыков посредством процесса исследования и использования сложных когнитивных процессов и языковых средств для решения потенциальных профессиональных проблем [5, р. 5-6; 8, р. 23].
CLIL-технология не только предоставляет контекст для обучения, но и делает это естественно и таким образом, чтобы имитировать то, как мы изучаем наш родной язык в детстве, а именно, в CLIL практически нет уроков грамматики. Студентов практически не обучают таким формализованным знаниям, как, например, структура предложения или спряжение глаголов - корректное соблюдение правил говорения гораздо важнее знания грамматики иностранного языка [13] - высокий уровень компетентности может быть достигнут в группах, где изучаемый язык является средством коммуникации, а не объектом детального анализа [9].

Важным фактором является то, что CLIL-технологии эффективно способствуют развитию мотивации студентов к изучению предмета (например, истории, юриспруденции, политологии и пр., куда он так стремился поступить абитуриентом и готовился к этому несколько лет) и косвенно направляет ее на изучение иностранного языка. Поскольку предмет и среда обучения взаимокоррелятивны, целевой язык в конечном итоге выигрывает от естественного интереса обучающихся к теме [13]. А именно, главной движущей силой к освоению иностранного языка является интерес к предмету, который обучающийся изучает в профессиональных целях и с которым ему предстоит работать на практике в будущем по окончании вуза.

Мнение специалистов на предмет того, какая именно должна быть структура занятия на основе CLILтехнологий в неязыковом вузе, разнится. Одни полагают, что обучение должно происходить посредством практических лекций-семинаров по профильным предметам. Например, при изучении поварского дела обучающиеся английскому языку наблюдают за действиями преподавателя в процессе приготовления мяса. При этом лекциясеминар проводится исключительно на целевом языке. Первую неделю обучающиеся практически не понимают язык, но со временем интерпретируют слова благодаря демонстрируемым практическим навыкам преподавателя и в конечном итоге запоминают, как называется то или иное действие / объект. Данный способ овладения языком через предметное содержание дисциплины аналогизирован с изучением языка в детстве, когда ребенок без уроков грамматики идет в дошкольное учреждение, уже хорошо владея речевыми навыками благодаря их соотношению в разговорной речи с реальными действиями и объектами [13] в процессе регулярного взаимодействия.

В вышеописанном примере представлена концепция максимального погружения в языковую среду:

(а) студенты приезжают в страну, где проходят обучение под руководством преподавателей-предметников - носителей иностранного языка;

(б) обучение происходит в интергруппе, поэтому 
студенты вынуждены использовать иностранный язык в качестве языка-посредника при общении друг с другом;

(в) после лекций и семинаров обучающиеся продолжают использовать иностранный язык для бытовой коммуникации (покупки в магазине, досуг, общение с соседями по кампусу / общежитию и пр.).

В данном примере практики CLIL структура занятий ничем не отличается от практических лекций и семинаров по направлению специальности в неязыковом вузе, в процессе которых студенты получают возможность приобретать знания, активно задействуя свои перцептивные и коммуникативные способности, а также логическое мышление.

При обучении в вузе вне языковой среды дисциплина преподается на иностранном языке, однако, коммуникация студентов с окружающими людьми после лекций и семинаров осуществляется на русском языке, поэтому процесс обучения длится гораздо дольше, чем в первом примере. В данном случае преподаватель должен владеть не только иностранным языком в профессиональной сфере, но и хорошо разбираться в предмете, который он преподаёт [9], или быть одновременно и преподавателем-предметником, и носителем целевого языка.

Для понимания и изучения неязыкового предмета активизируется широкий спектр когнитивных процессов. По мнению Coyle, D., Hood, P., Marsh, D. (2010), аудиторная практика CLIL предполагает, что студенты становятся активными участниками развития своего потенциала для приобретения знаний и навыков посредством процесса исследования (изучения), использования сложных когнитивных процессов и средств для решения проблем (инновационных) [5].

Таким образом, при изучении дисциплины через иностранный язык курс включает четыре области изучения: чтение, письмо, грамматику и анализ учебного материала по дисциплине неязыковой специальности. В процессе занятий студенты обнаруживают, что на самом деле они изучают «третий» язык - язык специальности, определенный вариант которого связан с конкретным предметом (физика, химия, математика, юриспруденция или история - в зависимости от направления подготовки), регулируемый профессионально ориентированной лексикой, грамматикой и стилем (материалы курса формируются в зависимости от предмета). Письмо охватывает правила, определения, историографию исследуемого вопроса, новости в мире данной науки об инновационных процессах и прочее, что способствует ясности изложения предложений, запоминанию шаблонов, цитат, профессиональных фразеологических оборотов и т.д.
Эти виды деятельности по содержанию мало чем отличаются от тех, которые реализовываются на курсах по предмету неязыковой специальности на родном языке. Эффективность подхода заключается в том, что данные виды учебной работы выполняются не ради них самих, а больше для того, чтобы помочь студентам развивать:

(1) способность анализировать на целевом языке в конкретной предметной области;

(2) критическое мышление;

(3) письменные навыки, которые им понадобятся в работе (некоторые студенты часто подрабатывают по своей специальности) или будут востребованы в перспективе.

Соответственно, структура занятий зависит от цели формирования профессиональных навыков и улучшения прагматических знаний иностранного языка, тем самым повышая способность обучающихся использовать коммуникативные элементы в действиях или применять на практике знания с использованием коммуникации, выражать, фиксировать, уточнять, анализировать и участвовать в диспутах с коллегами или сокурсниками, включая активное участие онлайн и офлайн коммуникации, что особенно актуально в период карантинных мер, введенных в период пандемии Covid-19, когда всё обучение перевели в дистанционный формат - формирование всех вышеперечисленных навыков является фундаментальными качествами при профессиональной деятельности, требующей использование иностранного языка (пилоты международных рейсов, журналисты, дипломаты и пр.).

По причине актуализации дистантного обучения все эти навыки современных студентов при обучении по CLIL-технологии проявляются в способности демонстрировать их в письменной форме и в онлайн/офлайн-деятельностях, а также в формате аудио-записей (так как большинство коммуникации в мессенджерах, в том числе, в рамках обучения по специальности среди сокурсников и с преподавателем) осуществляется посредством голосовых сообщений.

Учебный план и последовательность действий должны быть гибкими и адаптированными как под дистанционный, так и под очный форматы обучения, при этом в учебном процессе "уделяется особое внимание академическому содержанию как сути коммуникации» [4].

Вывод: актуальность использования CLIL-технологий в неязыковом вузе связана с возрастающей ролью полилингвистического пространства в профессиональной среде, детерминированной широкомасштабными миграционными процессами и активным налаживанием международных отношений в экономическом, образовательном и досуговом секторах. Структура занятий зависит от месторасположения вуза: (1) иностранное 
государство, в котором студент максимально погружается в языковую среду, а дисциплину преподает учитель-предметник, являясь при этом носителем языка. Структура занятий состоит из цикла лекций по всему курсу специальности на целевом языке; (2) отечественный вуз, где практические занятия и лекции проводятся на иностранном языке. В данном случае преподаватели обращаются к когерентно разработанным источникам учебного материала, позволяющие обучающимся использовать их предварительно накопленные знания для освоения дополнительного языкового и предметного содержания курса.
Применение CLIL-технологий в неязыковом вузе целесообразно при работе со студентами, имеющими уровень знания иностранного языка не ниже В2, так как целевой язык, наряду с родным, выступает как средство учебно-познавательной деятельности. Более того, студенты, слушающие курс по данной методике, начинают обучение с большей мотивацией, если имеют более высокий уровень владения иностранным языком, в противном случае их лингвистической компетенции будет недостаточно для понимания материала по профессионально ориентированным предметам, что снизит их познавательную активность и мотивационный потенциал.

\section{ЛИТЕРАТУРА}

1. Григорьева, К.С. Формирование у студентов технического вуза иноязычной компетенции в сфере профессиональной коммуникации на основе технологии CLIL: на примере направления «Техническая эксплуатация транспортного радиооборудования»: дис. ... кандидата педагогических наук: 13.00 .08 / Григорьева Ксения Сергеевна; [Место защиты: Казан. нац. исслед. технол. ун-т]. - Казань, 2016. - 223 с.

2. Диалог языков и культур в современном образовательном пространстве: материалы II международной научно-практической конференции (Россия, Воронеж, май 2020 г.) / Министерство сельского хозяйства РФ, ФГБО УВО «Воронежский государственный аграрный университет имени императора Петра ।», Гуманитарно-правовой факультет, Кафедра русского и иностранных языков; [ответственный редактор: Е.С. Саенко]. - Воронеж: Воронежский государственный аграрный университет имени императора Петра I, 2020. - 131 с.

3. Современная наука: от теории к практике: монография / Акзигитов А.Р., Афанасьева А.В., Бузин А.Н. [и др.]; под общей редакцией Г.Ю. Гуляева; Международный центр научного сотрудничества "Наука и просвещение". - Пенза: МЦНС "Наука и Просвещение", 2020. - 170 с.

4. Bruton, A.S. (2011) Is CLIL so beneficial, or just selective? Re-evaluating some of the research. System 39(4).

5. Coyle, D., Hood, P., Marsh, D. (2010). CLIL: Content and Language Integrated Learning. Cambridge University Press, Cambridge. - P. 5.

6. Darn, S. Content and Language Integrated Learning. British Council. URL: https://www.teachingenglish.org.uk/article/content-language-integrated-learning. Date: 04.02.2021.

7. Darn, S. Content and Language Integrated Learning (CLIL): A European Overview. URL: https://www.researchgate.net/publication/234652746 Content and Language Integrated Learning CLIL A European Overview. Date: 03.02.2021.

8. Dupuy, B.C. (2011) CLIL: Achieving Its Goals through a Multiliteracies Framework AICLE: El logro de sus objetivos a través de un marco multialfabetizaciones. Latin American Journal of Content \& Language Integrated Learning, 4(2), 21-32.

9. Gaballo, P. (2010) Integrating Content and Language in Specialized Language Teaching and Learning with the Help of Ict. URL: https://www.researchgate. net/publication/228742014_Integrating_Content_And_Language_In_Specialized_Language_Teaching_And_Learning_With_The_Help_0f_Ict. Date: 04.02.2021.

10. Goris J., EJPG Denessen, LTW Verhoeven (2019) Effects of content and language integrated learning in Europe A systematic review of longitudinal experimental studies. European Educational Research Journal 18(2):147490411987242.

11. Kern, R. (2000). Literacy and language teaching. Oxford, UK: Oxford University Press.

12. Nguyen, Thi (2019) Content and language integrated learning in Vietnam: evolution of students' and teachers' perceptions in an innovative foreign language learning system.

13. Stevie, D. CLIL:What It Is, and Why Language Teachers Will Find It Delightful. URL: https://www.fluentu.com/blog/educator/what-is-clil/. Date: 04.02.2021.

( П Пономарева Алиса Владиславовна (avponomareva@fa.ru), Яковлева Екатерина Николаевна (enyakovleva@fa.ru).

Журнал «Современная наука: актуальные проблемы теории и практики» 